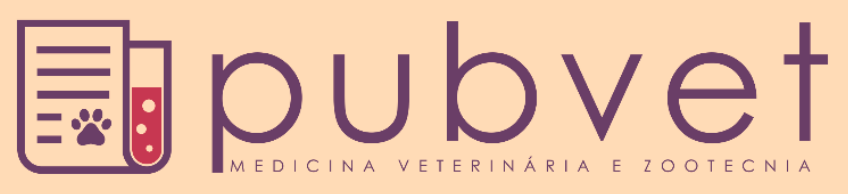

https://doi.org/10.31533/pubvet.v13n8a381.1-7

\title{
Nova abordagem cirúrgica para o tratamento do prolapso da glândula da terceira pálpebra em cães: Estudo retrospectivo
}

\author{
Marcela Cristiane Pereira ${ }^{1}$, Flávia de Melo Barbosa ${ }^{1}$, Luiz Fernando Lucas Ferreira ${ }^{2 *} \bullet$, \\ Amanda Ladeia Fernandes ${ }^{1}$, Bruna Ferraz Calhau ${ }^{1}$ 。 \\ 1.Graduandas em Medicina Veterinária, Pontifícia Universidade Católica de Minas Gerais,(PUC Minas-Betim). \\ 2.Médico Veterinário e Professor da Pontifícia Universidade Católica de Minas Gerais, Departamento de Medicina \\ Veterinária, Betim - MG Brasil. E-mail:lfvet@hotmail.com.
}

Resumo. Em um estudo realizado em doze cães, 13 olhos, com apresentação clínica de prolapso da glândula da terceira pálpebra, objetivou-se o tratamento cirúrgico do mesmo, por uma nova abordagem cirúrgica. Após exame oftalmológico completo e laboratoriais pré-cirúrgico, procedeu-se o tratamento cirúrgico do prolapso da glândula da terceira pálpebra: através de incisão com uso de laser cirúrgico na face caudal a base da terceira pálpebra promoveu-se, com auxílio de uma pinça mosquito curva, um túnel por meio da divulsão na mucosa. Por meio de duas suturas de Wolf com fio absorvível de modo que esse transpasse a terceira pálpebra e a mucosa divulsionada, de maneira que a glândula prolapsada fique sepultada pela manobra da sutura, ficando retida no interior da mucosa da face caudal da terceira pálpebra. As duas suturas demonstram-se suficientes para impedir que a glândula reprolapsa-se. Todos os pacientes foram avaliados após o procedimento sete, quatorze e vinte e um dias pós-cirurgia, nenhum destes apresentaram recidiva do prolapso nem mesmo inflamação da glândula, conjuntiva ou alteração na sua produção lacrimal.

Palavras chave: cães, cirurgia, produção lacrimal, prolapso da glândula de terceira pálpebra

\section{New surgical approach for the treatment of gland prolapse of the third eyelid in dogs: A retrospective study}

\begin{abstract}
At this clinical study twelve dogs, 13 eyes, presenting the prolapse of the third eyelid gland, received surgical treatment in a new technical approach. After a complete eye exam and pre-surgery laboratory exams, the surgical treatment of the prolapse of the third eyelid gland was performed through an incision, using a surgical laser on the caudal side of the base of the third eyelid; a tunnel was created by divulsion the mucosa using a HalstedMosquito forceps. The prolapsed gland was replaced by performing two Wolf's sutures with absorbable thread trespassing the third eyelid and its inner mucosa. This procedure was enabled to retain the prolapsed gland inside the mucosa of the caudal face of the third eyelid. The two sutures were sufficient to prevent the gland from reprofiling itself. All patients were evaluated after seven, fourteen and twenty-one days post- surgery, none of them presented recurrence of prolapse or even inflammation of the gland, conjunctiva or alteration in their lacrimal production.
\end{abstract}

Keywords: dogs, lacrimal production, prolapse of the gland of the third eyelid, surgery 


\title{
Nuevo enfoque en el tratamiento quirúrgico para el tratamiento de la glándula del tercer párpado en perros: Estudio retrospectivo
}

\begin{abstract}
Resumen. En un estudio realizado con doce perros, 13 ojos, con presentación clínica del prolapso de la glándula del tercer párpado, se objetivó el tratamiento quirúrgico del mismo a través de un nuevo abordaje quirúrgico. Después del examen oftalmológico completo y de exámenes de laboratorio, se procedió al tratamiento quirúrgico del prolapso de la glándula del tercer párpado: a través de incisión con uso de láser quirúrgico en el lado caudal, la base del tercer párpado se viabilizó, con ayuda de una pinza mosquito curva, un túnel por medio de la divulsión en la mucosa, de manera que la glándula prolapsada quede oculta por la maniobra de la sutura, siendo retenida en el interior de la mucosa del área caudal del tercer parpado.. Las dos suturas demuestran ser eficientes para evitar que la glándula se prolapse nuevamente. Todos los pacientes fueron evaluados después del procedimiento. Siete, catorce y veintiún días después de la cirugía ninguno de ellos presentó reincidencia del prolapso ni inflamación de la glándula, conjuntiva o alteración en su producción lagrimal.
\end{abstract}

Palabras claves: cirugía, perros, producción lagrimal, prolapso de la glándula del tercer párpado

\section{Introdução}

O prolapso da glândula lacrimal é uma afecção comum em cães, que acomete preferencialmente os braquicefálicos, sendo que algumas raças específicas possuem uma predisposição para essa afecção não possui prevalência em machos ou fêmeas e podendo apresentar-se unilateral ou bilateral (Santoset al.,2012). Caracteriza-se por ser um crescimento e inflamação da glândula lacrimal presente na terceira pálpebra, fazendo com que ela se projete para fora da membrana. O prolapso da glândula lacrimal ocorre devido à fraqueza do ligamento que une a glândula ao globo ocular (Fossum,2014; Santoset al.,2012). Sua causa ainda não está totalmente esclarecida na literatura, onde normalmente está associada a traumas e a genética para algumas raças específicas.

O principal sinal clínico é a apresentação de uma "massa avermelhada" no canto medial do olho (Gelatt,2003). Seu diagnóstico é realizado por uma anamnese e exame clínico minucioso, realizado pelo médico veterinário (Queirozet al.,2015). Entre os diagnósticos diferenciais tem-se a protrusão da terceira pálpebra em casos de neoplasias da terceira pálpebra, além de doenças sistêmicas que podem ser diagnósticos diferenciais como a raiva e o tétano, porém essas não são comuns na clínica de pequenos animais (Santoset al.,2012).

O seu tratamento é preferencialmente cirúrgico e consiste na recolocação da glândula lacrimal na sua posição anatômica, devido outros tratamentos não apresentarem um resultado satisfatório. Não se recomenda a retirada da glândula lacrimal prolapsada, pois ela é responsável pela produção da fração aquosa do filme lacrimal do olho, sendo fundamental para o seu funcionamento (Fossum,2014). Em caso da remoção cirúrgica do prolapso da glândula da terceira pálpebra existem consequências, sendo a principal a ceratoconjutivite seca (CCS) (Ranzaniet al.,2004).

São diversas as técnicas cirúrgicas descritas na literatura para o reposicionamento da glândula lacrimal, sendo que na sua maioria obtêm-se sucesso no procedimento cirúrgico e no pós-cirúrgico, apresentando um bom resultado na resolução dessa afecção. As técnicas descritas na literatura são as Técnicas de Ancoragem (Técnica de Blogg 1979, Técnica de Kaswan \& Martin 1985 e a Técnica de Stanley \& Kaswan 1994) e as Técnicas de Bolso (Técnica de Moore 1983 e Técnica de Morgan 1993) (Gelatt,2003; Slatter,2007).

O objetivo deste trabalho é relatar um experimento sobre a eficácia de uma nova abordagem cirúrgica no tratamento do prolapso da glândula da terceira pálpebra em cães, onde à incisão é realizada com laser cirúrgico, sendo executadas duas suturas do tipo Wolf, ficando essas posicionadas na face rostral da terceira pálpebra, sendo o fio da sutura do tipo absorvível. 


\section{Material e métodos}

O protocolo dessa pesquisa foi aprovado pelo o Comitê de Ética no Uso de Animais da PUC Minas (CEUA PUC Minas), com número de protocolo 005/2017. Ao término do projeto os animais voltaram aos seus respectivos lares com seus tutores.

Doze cães, machos e fêmeas, de diferentes raças, adultos e filhotes, admitidos como sadios, com idade variando entre 3 meses e 12 anos, com diagnóstico de prolapso da glândula da terceira pálpebra, provenientes de consultas realizadas no Hospital Veterinário da PUC Minas de Betim e na Clínica Veterinária Professor Israel de Belo Horizonte, foram selecionados para realizar o procedimento cirúrgico do prolapso da terceira pálpebra após exames clínicos, oftálmicos e complementares.

Por se tratar de uma nova abordagem cirúrgica os tutores foram informados do procedimento e formalizaram autorização por escrito conforme modelo do CEUA - PUC Minas.

Os animais foram encaminhados para o Hospital Veterinário da PUC Minas de Betim e para Clínica Veterinária Professor Israel no dia marcado para realização do procedimento cirúrgico sendo realizado previamente o jejum alimentar e hídrico que foi solicitado pelo médico veterinário aos seus tutores no dia da marcação da cirurgia, onde esses foram mantidos em canis individuais. $\mathrm{O}$ local do procedimento cirúrgico foi o mesmo onde os pacientes realizaram as consultas. Na tabela 1, demonstra a distribuição dos animais de acordo com a raça, idade, sexo e lateralidade do olho operado.

Tabela 1. Relação dos animais que foram submetidos ao procedimento cirúrgico de sepultamento da glândula da terceira pálpebra

\begin{tabular}{|c|c|c|c|c|c|}
\hline Animal & Espécie & Raça & Idade & Sexo & Olho Operado \\
\hline$\overline{\text { Olga }}$ & Canina & Buldog Francês & 12 anos & $\bar{F}$ & Direito \\
\hline Leia & Canina & York Shire Terrier & 7 anos & $\mathrm{F}$ & Direito \\
\hline Godofredo & Canina & Buldog & 2 anos & M & Direito \\
\hline Pandora & Canina & Shis Tzu & 2 anos & $\mathrm{F}$ & Direito \\
\hline Bartolomeu & Canina & Buldog Francês & 2 anos & M & Direito \\
\hline Amon & Canina & Rotweiller & 1 ano & M & Direito \\
\hline Nina & Canina & Buldog Francês & 1 ano & $\mathrm{F}$ & Direito \\
\hline Brigite & Canina & Poodle & 2 anos & $\mathrm{F}$ & Direito \\
\hline Poto & Canina & Lulu da Pomerania & 1 ano & M & Direito \\
\hline Zeus & Canina & Buldog Francês & 1 ano & M & Esquerdo \\
\hline Margot & Canina & Buldog & 9 meses & $\mathrm{F}$ & Esquerdo \\
\hline Scooby & Canina & Beagle & 3 meses & M & Bilateral \\
\hline
\end{tabular}

Foram realizados em todos os animais o exame de rotina da clínica, onde foram avaliados os parâmetros respiratório, cardíaco, aferida temperatura e anamnese completa. Os seguintes exames pré cirúrgicos de rotina foram realizados: hemograma, perfil bioquímico e eletrocardiograma. Exames oftálmicos auxiliares foram realizados como o Teste Lacrimal de Schirmer (TLS), que é utilizado para avaliar a produção quantitativa de lágrima. Foi aplicado nos dois olhos o colírio de fluoresceína, para avaliar a integridade do epitélio corneano. Nenhum dos animais avaliados apresentou alterações nos exames aos quais foram submetidos, estando todos aptos a realizarem o procedimento cirúrgico. Quanto ao resultado do TLS e do colírio de fluoresceína, todos os pacientes apresentaram produção lacrimal bilateral maior que $15 \mathrm{~mm}$ e integridade do epitélio corneano, ou seja, ausência de úlcera de córnea em ambos os olhos.

Para o procedimento cirúrgico, os cães receberam como medicação pré-anestésica (MPA) xilazina $2 \%$ (Dopaser - cloridrato de xilazina 2\% - Hertape Calier, Brasil), na dose de 0,5 mg/kg/IM associada à morfina (Dimorf - sulfato de morfina - Cristália, Brasil), na dose de 0,2 mg/kg/IM, aplicadas na mesma seringa. Como anestésico local, foi utilizado colírio de tetracaína, instilando uma gota a cada trinta segundos num total de três gotas, previamente ao início da cirurgia e da antissepsia local com solução de P.V.P.I. tópico e solução fisiológica de $\mathrm{NaCl}$ 0,9\% estéril (Solução de Cloreto de Sódio 0,9\% - Laboratório Sanobiol Ltda., São Paulo -SP, Brasil). 
Após a MPA foi providenciado acesso da veia cefálica direita com cateter 22G (Cateter Angiocath BD - 22G - São Paulo - SP, Brasil) e manutenção de fluidoterapia com solução de cloreto de sódio a $0,9 \%$, em infusão calculada pela dose de $10 \mathrm{ml} / \mathrm{kg} / \mathrm{h}$. A indução anestésica foi feita logo após a realização do acesso venoso com propofol (Propovan - propofol 1\% - Cristália, Brasil) na dose de 2,0 a 4,0 $\mathrm{mg} / \mathrm{kg} / \mathrm{IV}$, observando-se perda de reflexos e permitindo a intubação orotraqueal.

A manutenção anestésica foi feita com isoflurano (Forane - isolflurano - Abbott, Brasil), diluído em oxigênio $100 \%$ pelo uso de vaporizador universal, em circuito de reinalação parcial de gases, utilizandose para controle da profundidade os planos de Guedel.

O procedimento cirúrgico foi realizado com aparelho de laser cirúrgico, THERAVET, regulado para emissão de radiação de laser na potência de $3000 \mathrm{~mW}$ (Figura1), estando o paciente anestesiado e em decúbito external e com o olho a ser operado higienizado com solução P.V.P.I. tópico e solução fisiológica, procedeu-se a tração rostral da terceira pálpebra com auxílio de uma pinça de Allis (Figura2), em seguida uma incisão caudal na base da glândula da terceira pálpebra foi realizada com o laser cirúrgico (Figura3).

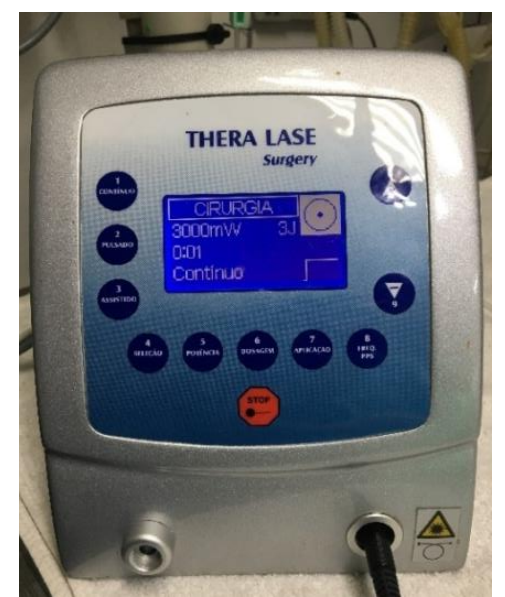

Figura 1. Aparelho de laser cirúrgico, THERAVET, regulado para emissão de radiação de laser na potência de $3000 \mathrm{~mW}$.

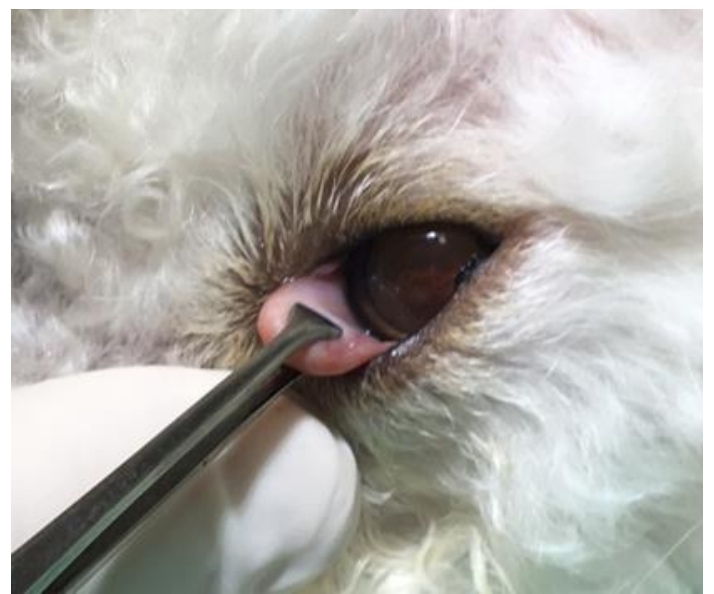

Figura 2. Tração rostral da glândula da terceira pálpebra com auxílio de uma pinça de Allis

Utilizando uma pinça mosquito curva, foi realizado um túnel pela divulsão da mucosa (Figura4). Uma sutura de Wolf com fio 4-0 absorvível, Poliglecaprone 25 (Caprofyl),foi realizada iniciando-se na face rostral da terceira pálpebra transpassando a mesma por completo e em seguida transpassando a mucosa já divulsionada (Figura5 A eB), sendo esse trajeto da sutura repetido de forma contraria para que o nó da sutura ficasse alocado na face rostral da terceira pálpebra. Consequentemente, a glândula prolapsada foi sepultada pela manobra da sutura, ficando a mesma retida no interior da mucosa da face caudal da terceira pálpebra (Figura 6). Foram realizados dois pontos do tipo Wolf.

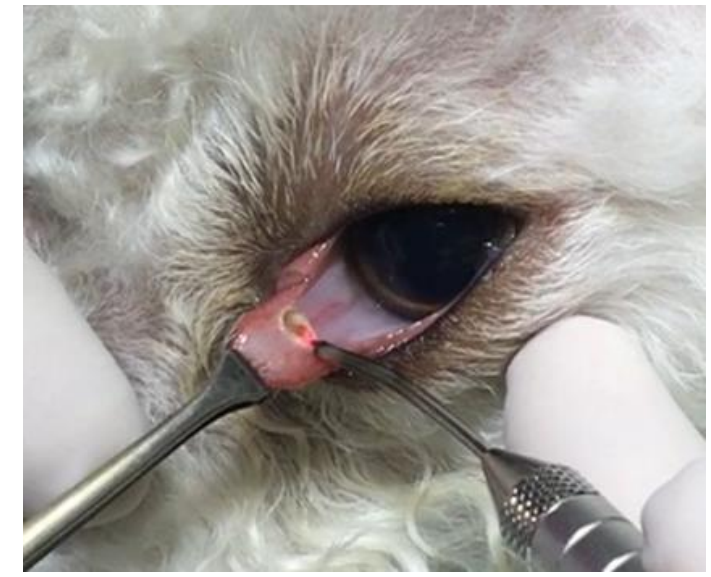

Figura 3. Incisão na base caudal da glândula da terceira pálpebra realizada com o laser cirúrgico

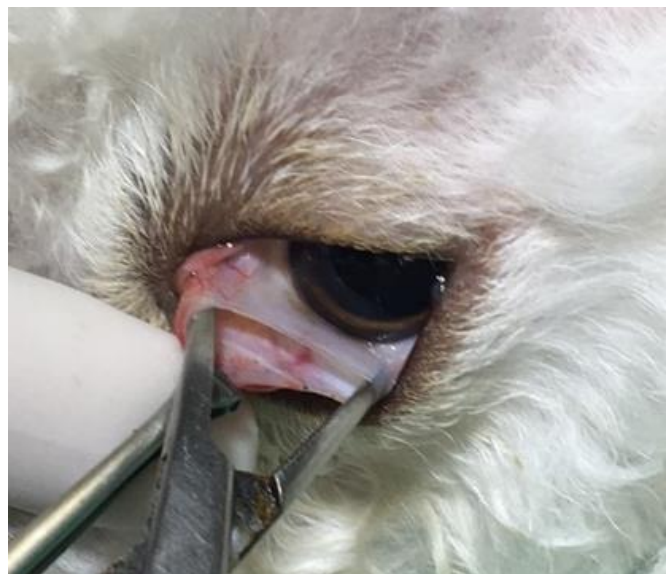

Figura 4. Divulsão da mucosa utilizando pinça mosquito curva, criando um túnel para realizar o sepultamento da glândula prolapsada 

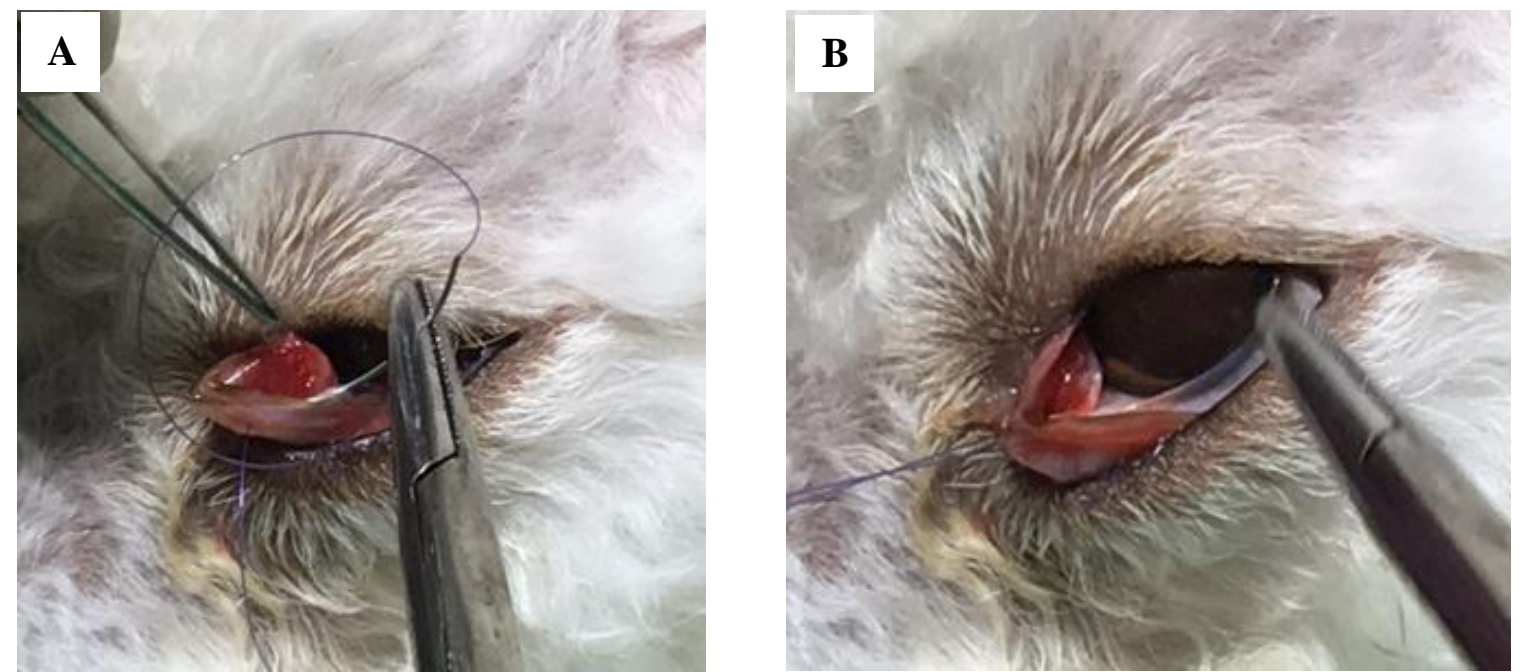

Figura 5. (A) Sutura de Wolf com fio 4-0 absorvível Poliglecaprone 25 (Caprofyl), iniciando-se na face rostral da terceira pálpebra, transpassado a mesma por completa e em seguida transpassando a mucosa já divulsionada,(B) repetindo o trajeto de forma contraria para que o nó da sutura fique alocado na face rostral da terceira pálpebra.

O cuidado para o pós-operatório constituiu-se do uso de colírio anti-inflamatório e antibiótico,(CILODEX - ciprofolaxina e dexametasona) quatro vezes ao dia, durante sete dias. Houve recomendação da utilização de colar elisabetano para evitar possível lesão ocular causada pelo esfregar dos olhos. Os pacientes fizeram retornos clínicos a cada sete dias para avaliação da cirurgia (Figura7), sendo um total de três retornos (7, 14 e 21 dias). Por ser o fio da sutura absorvível, não houve remoção do mesmo.

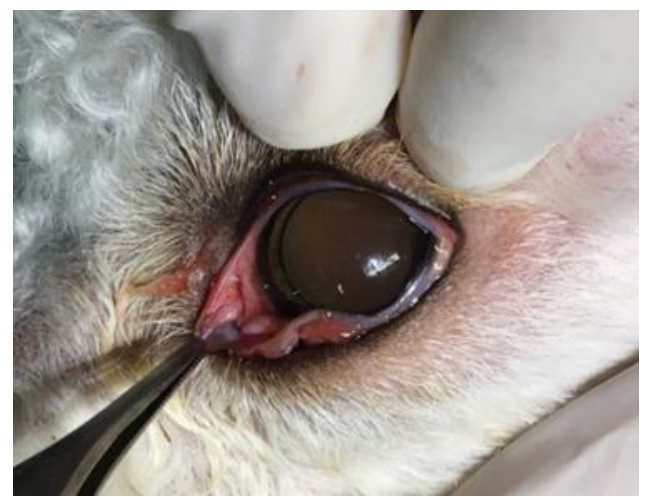

Figura 6. Aspecto do olho após a glândula prolapsada ser sepultada pela manobra da sutura, ficando a mesma retida no interior da mucosa da face caudal da terceira pálpebra

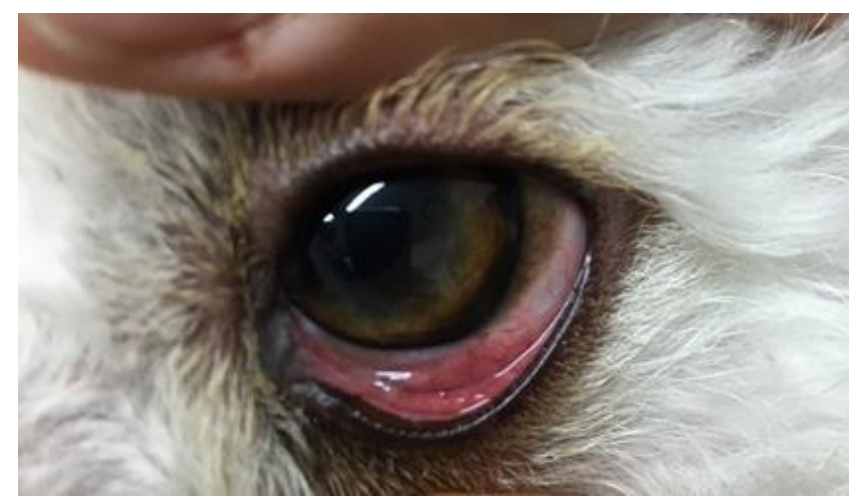

Figura 7. Avaliação pós-operatório do olho do paciente sete dias após o procedimento cirúrgico de sepultamento da glândula da terceira pálpebra

\section{Resultados e discussão}

A técnica proposta no presente estudo demonstrou-se eficaz uma vez que $100 \%$ dos olhos operados apresentaram resultado estético e funcional satisfatório não havendo nenhum caso de recidiva do prolapso, ocorrência de úlceras de córnea e diminuição da produção de lágrima.

Sete dos doze cães operados são de raça braquicefálica, resultado esse que corrobora com os achados da literatura a qual relata que essa afecção é preferencialmente observada em cães braquicefálicos e com predisposição em algumas raças especificas (Dehghanet al.,2012; Raiset al.,2015; Santoset al.,2012). No presente estudo dez dos doze cães avaliados e tratados estavam em idade inferior a três anos, concordando com Dehghanet al.(2012), que relatam que essa afecção atinge animais com idade entre 1 a 3 anos, sendo que a maioria dos casos é diagnosticado com até 2 anos de idade, contudo para Peixoto\&Galera(2012) a idade varia de dois meses a 13 anos. A afecção em estudo foi mais frequentemente diagnosticada no olho direito, sendo menos frequente no olho esquerdo e bilateral (Peixoto\&Galera,2012). Nove dos doze cães operados apresentaram prolapso no olho direito, seguido de dois cães no olho esquerdo e apenas um bilateral. 
A reintrodução manual e o tratamento tópico com pomadas oftalmológicas que consistem em antibióticos e agentes corticoides conseguem apenas uma resposta temporária, sendo o tratamento cirúrgico o de escolha pelos médicos veterinários oftalmologistas (Delgado,2005; Wouket al.,2009). Nas técnicas descritas para o reposicionamento da glândula da terceira pálpebra é obrigatório aplicar suturas transfixantes ao tecido glandular para fazer um ancoramento, que induz lesões à barreira hematolacrimal (Ettinger\&Feldman,2004; Feldman,1997; Jericóet al.,2015). A técnica de bolso, ou sepultamento, consiste em aplicar a sutura de modo em que os pontos fiquem na face bulbar da terceira pálpebra, permitindo maior segurança e preservação da córnea, evitando contato dos pontos com a face ventral do olho, pois o contato contínuo do fio pode levar a uma úlcera de córnea (Dehghanet al.,2012; Ettinger\&Feldman,2004; Feldman,1997; Jericóet al.,2015). No experimento de Plummeret al.(2008) foi utilizado uma sutura com fio não absorvível, náilon, 4-0, para ancorar a glândula prolapsada na cartilagem da terceira pálpebra, os pontos ficaram ancorados na superfície anterior da terceira pálpebra. Especula-se que o uso do fio não absorvível pode trazer consequências como pruridas intensas e contínuas, formação de fibrose e reação de corpo estranho com formação de fistula.

Na técnica utilizada no presente experimento foram utilizados dois pontos do tipo Wolf com fio 4-0 absorvível,Poliglecaprone 25 (Caprofyl), onde os nós ficam na face rostral da terceira pálpebra onde à ausência do contato do fio com a córnea, sendo os dois pontos suficientes para que a glândula nictitante não volte a se prolapsar. Como o fio é do tipo absorvível, não é necessário fazer sua remoção póscirurgia, pois o seu material é progressivamente destruído e absorvido pela ação de hidrólise, proteólise e consequentemente pela fagocitose, perdendo sua força de resistência, o fio será totalmente absorvido dentro de no máximo 91 a 119 dias pelo organismo (Quessadaet al.,1995). Três animais que voltaram à clínica, cerca de seis meses pós-cirurgia para aplicação de vacina e realização de outros exames, foi constado a ausência do fio de sutura, o que demonstrou que a absorção foi completa e sem presença de lesões na córnea, fibrose conjuntival ou conjuntivite.

Segundo Ettinger\&Feldman(2004) e Jericóet al.(2015) foram relatados casos em que houve discretas inflamações nas glândulas lacrimais prolapsadas tratadas cirurgicamente. No presente experimento os animais que foram avaliados posteriormente a cirurgia, não apresentaram casos de inflamação da glândula e nem da conjuntiva. Sendo que nenhum dos animais apresentou recidiva do prolapso e todos tiveram o resultado do Teste Lacrimal de Schirmer satisfatório, maior que $15 \mathrm{~mm}$. Esses resultados podem ser justificados pelo uso do colírio anti-inflamatório e antibiótico (CILODEX - ciprofolaxina e dexametasona) no pós-cirúrgico e pela incisão com laser. Nas técnicas cirúrgicas descritas de ancoragem e de bolso para o reposicionamento da glândula da terceira pálpebra é utilizado lâmina de bisturi para realizar a incisão na conjuntiva da face palpebral da membrana nictitante (Ettinger\&Feldman,2004; Jericóet al.,2015). Neste estudo foi utilizado o aparelho de laser cirúrgico. O uso do laser permite uma incisão com ausência de sangramento no campo cirúrgico, trazendo eficácia e benefícios para a visão do cirurgião, diminuindo o tempo cirúrgico. Cabralet al.(2008) constataram que os animais submetidos ao sepultamento cirúrgico da glândula apresentaram maior produção de lágrima quando comparados àqueles que mantiveram as glândulas prolapsadas ou que tiveram a mesma removida. A CCS foi encontrada na maioria dos animais que permaneceram com o prolapso da glândula da terceira pálpebra, porém quando é feita a remoção cirúrgica da glândula mostrou-se uma redução considerável nos valores do TLS. Entretanto, mesmo quando é feito o reposicionamento cirúrgico da glândula não é garantido que o animal não desenvolva a CCS, pois os animais acometidos pelo prolapso da glândula da terceira pálpebra podem também possuir predisposição para esse tipo de afecção (Edelmannet al.,2013). Todos os animais que passaram pelo procedimento cirúrgico do presente experimento foram submetidos ao Teste Lacrimal de Schirmer antes e após a cirurgia, onde ficou constatado que nenhum deles apresentou diminuição na produção lacrimal.

\section{Conclusão}

No presente estudo a nova abordagem cirúrgica mostrou-se eficaz no tratamento do prolapso da glândula da terceira pálpebra devido a utilização do laser cirúrgico que realiza uma incisão na mucosa com ausência de sangramento e diminuição do tempo da cirurgia, além do posicionamento dos nós das suturas ficarem alocados na face rostral da terceira pálpebra evitando assim seu contato com a córnea e as duas suturas realizadas se mostrarem suficientes para evitar recidiva do prolapso. Ressaltando que no 
pós-operatório houve ausência de reações inflamatórias aparentes, úlcera de córnea e interferência na produção de lágrimas. Deve-se, entretanto, considerar o número de olhos operados, 13 olhos, sinalizando para futuros estudos os quais podem conter maior número de cirurgias realizadas com acompanhamento por período prolongado.

\section{Referências bibliográficas}

Cabral, V. P., Watanabe, E., Tostes, R. A., Simonelli, S. M. \& Laus, J. L. (2008). Third eyelid gland protrusion in dogs: an experimental model proposal. Ciência Rural,38(7):1920-1924.

Dehghan, M. M., Pedram, M. S., Azari, O., Mehrjerdi, H. K. \& Azad, E. (2012). Clinical evaluation of the pocket technique for replacement of prolapsed gland of the third eyelid in dogs. Turkish Journal of Veterinary and Animal Sciences,36(4):352-356.

Delgado, E. (2005). Recolocação cirúrgica da glândula da membrana nictitante em canídeos pela técnica de bolsa conjuntival - 23 casos clínicos. Revista Portuguesa de Ciências Veterinárias89-94.

Edelmann, M. L., Miyadera, K., Iwabe, S. \& Komáromy, A. M. (2013). Investigating the inheritance of prolapsed nictitating membrane glands in a large canine pedigree. Veterinary Ophthalmology, 16(6):416-422.

Ettinger, S. \& Feldman, E. (2004). Tratado de medicina interna veterinária: doenças do cão e do gato. Rio de Janeiro: Guanabara Koogan.

Feldman, E. C. (1997). Tratado de medicina interna veterinária(Vol. 3).

Fossum, T. W. (2014). Cirurgia de pequenos animais(4 ed. Vol. 1). São Paulo: Elsevier Brasil.

Gelatt, K. N. (2003). Manual de oftalmologia veterinária. Barueri, São Paulo, Brasil: Editora Monole.

Jericó, M. M., Kogika, M. M. \& Andrade Neto, J. P. (2015). Tratado de medicina interna de cães e gatos. Rio de Janeiro, Brasil: Guanabara Koogan.

Peixoto, R. V. \& Galera, P. D. (2012). Avaliação de 67 casos de protrusão da glândula da terceira pálpebra em cães (2005-2010). Arquivo Brasileiro de Medecina Veterinária e Zootecnia,64(5):11511155.

Plummer, C. E., Källberg, M. E., Gelatt, K. N., Gelatt, J. P., Barrie, K. P. \& Brooks, D. E. (2008). Intranictitans tacking for replacement of prolapsed gland of the third eyelid in dogs. Veterinary Ophthalmology, 11(4):228-233.

Queiroz, S. E., Silva, A., A. C. H. \& Yoshio, W. (2015). Estudo retrospectivo da ocorrência do prolapso de glândula da terceira pálpebra em cães. Nosso Clínico São Paulo,1858-62.

Quessada, A. M., Muniz, L. M. R., de Sousa, J. M. \& Drumond, K. O. (1995). Sutura extramucosa em pontos separados simples e plano único no esôfago torácico de cães. Veterinária em Foco,7(2):165-174.

Rais, A., Sankhala, L. N., Saini, R. K., Shringi, A. \& Gahlot, M. (2015). Surgical management of cherry eye in Rottweiler dog. International Journal of Science, Environment and Technology,4999-1001.

Ranzani, J. J. T., Brandão, C. V. S., Rodrigues, G. N., Cremonini, D. N., Peixoto, T. P., Lima, L. S. A. \& Chiurciu, J. V. L. (2004). Prolapso da glândula da terceira pálpebra em cães: comparação entre duas técnicas de reposicionamento. Brazilian Journal of Veterinary Research and Animal Science,4162-63.

Santos, I. F. C., Cardoso, J. M. M., Del Poente, M. D., Silva, L. F. \& Castro, N. C. N. (2012). Prolapso da glândula da terceira pálpebra em cão-relato de caso. Acta Veterinaria Brasilica,6(4):329-334.

Slatter, D. H. (2007). Manual de cirurgia de pequenos animais. São Paulo: Manole.

Wouk, A. F. P. F., Souza, A. L. G. \& Farias, M. R. (2009). Afecções dos anexos oftálmicos. In J. L. Laus (Ed.), Oftalmologia clínica e cirúrgica em cães e em gatos(pp. 58-62). São Paulo, Brasil: Editora Roca.

Recebido: 11 de junho, 2019.

Aprovado: 7 de julho, 2019.

Publicado: 26 de agosto, 2019.

Licenciamento: Este artigo é publicado na modalidade Acesso Aberto sob a licença Creative Commons Atribuição 4.0 (CC-BY 4.0), a qual permite uso irrestrito, distribuição, reprodução em qualquer meio, desde que o autor e a fonte sejam devidamente creditados 